\title{
Organization of surgical services and operating room efficiency in Norwegian hospitals
}

\author{
Dag Bratlid ${ }^{1,2,3}$, Svein Petter Raknes ${ }^{4}$ \\ 1. Institute for Laboratory Medicine, Children's and Women's Health, Faculty of Medicine, Norwegian University of Science \\ and Technology, Norway. 2. Department of Pediatrics and Adolescent Medicine, St. Olavs University Hospital, Trondheim, \\ Norway. 3. Department of Health Management and Health Economics, Institute of Health and Society, Faculty of Medicine, \\ University of Oslo, Oslo, Norway. 4. Hospitalitet AS, Lysaker torg, Lysaker, Norway
}

Correspondence: Dag Bratlid. Address: Institute for Laboratory Medicine, Children's and Women's Health, Faculty of Medicine, Norwegian University of Science and Technology, Norway. E-mail: dag.bratlid@ntnu.no

Received: November 26, 2012 Accepted: December 25, 2012 Online Published: January 4, 2013

DOI : 10.5430/jha.v2n2p61 URL: http://dx.doi.org/10.5430/jha.v2n2p61

\section{Abstract}

Background: Most studies on operating room (OR) efficiency have focused on how local factors within the surgical facilities (micro level), such as turnover time, case duration and non-operative time, affects operating room efficiency. Few studies have analyzed how different strategies for organizing surgical services on the departmental or hospital level (macro level) might affect OR efficiency.

Norwegian hospitals have organized their surgical services on the macro level along two different strategies. Most hospitals have separate facilities for out-patient surgery and in-patient surgery, often also geographically separated. Most hospitals also have specialty specific OR (orthopedics, gastroenterology, gynecology etc.), while in other hospitals different subspecialties share the same OR. This study was undertaken to analyze any effect of these different organizational strategies in relation to productivity and OR efficiency.

Methods: Data on organization of surgical services and operation volume for 2009 was gathered from eleven Norwegian university and larger county hospitals with a similar case mix. Total OR efficiency and OR efficiency during ordinary work hours were analyzed separately for out-patient and in-hospital surgery, including emergency operations. Calculation of OR during ordinary hours (8am-3pm) was based on 230 workdays per year, and included emergency operations.

Results: Surgeon competence and productivity was similar in the included hospitals and productivity was not related to organization of surgical services on the macro level. OR efficiency was 701 operations per OR per year with a range from 525 to 823 and was not related to the different strategies for organizing these services. Furthermore, no correlation was found between OR efficiency and operation volume or number of ORs. OR efficiency during ordinary hours and workdays was 3.6 operations per day for out-patient surgery and 1.8 for in-patient surgery including emergency operations. This was considerably less than standards used in planning surgical facilities in Norwegian hospitals.

Conclusion: Productivity and OR efficiency are probably more related to organization of the surgical services on the micro level than to strategies for organizing these services on the macro level. The large variation in operating room efficiency in Norwegian hospitals with similar productivity indicates that many hospitals have a potential for improvement. The discrepancy between actual OR efficiency and standards used for planning of surgical facilities represents a challenge in future hospital planning.

\section{Key words}

Operation room efficiency, Organization of surgical services, Out-patient surgery, Standards

Published by Sciedu Press 


\section{Background}

Surgical facilities are among the most expensive units in a modern hospital, both in relation to planning, construction and daily operative costs. Productivity and operating room efficiency is therefore of significant importance to hospital economics as well as patient satisfaction. Most studies on operating room efficiency have focused on elements such as turnover time, case duration, non-operative time, tardiness, and factors related to team members motivation and discipline ${ }^{[1-9]}$, by us defined as related to organization on the micro level. Few studies have, however, focused on how separate operating rooms for out-patients and in-patients, or organization with subspecialty specific or shared operating rooms, by us defined as organization on the macro level have impact on operating room efficiency.

In Norway, most hospitals have organized their surgical services with separate facilities for out-patient surgery, often also geographically separated in order to shield these procedures from other activities and emergency procedures. Also, most hospitals have organized these services with specialty specific operating rooms (orthopedics, gastroenterology, gynecology etc.), while other hospitals have a strategy with shared use of the same operating rooms by the different subspecialties.

This study was therefore undertaken to analyze any effect of these different organizational strategies for surgical services on the macro level in relation to productivity and operating room efficiency. The study also wanted to analyze if daytime operating room efficiency (operations per operating room per day during ordinary work hours) was in compliance with set recommendations used in planning surgical facilities in future hospitals.

\section{Materials and methods}

\subsection{Data accretion}

In March 2010 a questionnaire related to details on organization and volume of surgical services in 2009 was submitted by e-mail to hospital directors/directors of surgery (who were mostly medical doctors) at Norwegian university hospitals and larger county hospitals located around the country. The questions were: How many operating rooms did the hospital have this year? Was surgery organized with separate operating rooms for out-patient and in-patient surgery, and, if so, how many operating rooms were reserved for out-patient surgery, and how many were reserved for in-patient surgery? How many out-patient operations and in-patient operations (including emergency operations) were performed during 2009 ? The hospitals were also asked whether surgical services were organized with different subspecialties sharing operating rooms or with separate facilities for each subspecialty. The study included only administrative data on number of operations performed and number of operating rooms with no identifiable patient data such as age, gender, diagnosis, time of operation or similar. In Norway such studies do not need approval by the Regional Research Ethics Committee.

Eleven out of twelve hospitals responded positively to the questionnaire. Included hospitals had the same mix of different surgical subspecialties with some exceptions. Neurosurgery is in Norway only located at university hospitals. Also, some low volume patients such as organ transplants, pediatric cardiac surgery, neonatal surgery, operations on congenital malformations and others are centralized to one or two hospitals, as previously reported ${ }^{[10]}$.

After the received information and data had been reviewed and organized, it was sent back to the person appointed at each hospital for quality control and supplementary information. For several of the hospitals it was necessary with repeat contacts to clear misunderstandings both on the hospital and on the investigators side. Some hospitals also actively contacted the investigators to improve data quality. Major threats to validity of the data were the lack of routine administrative systems in many hospitals for consecutive registration of such data. This resulted in a significant workload 
in many hospitals to be able to report valid data. This was also the reason why one large hospital declined to participate in the study. By the end of 2010 data aggregation was closed.

In analyses of data from each hospital, operations in different subspecialties (general surgery, orthopedics, ophthalmology, gynecology, etc.) were combined into one surgical volume for each hospital. The information from the hospitals on organization with separate facilities for out-patient surgery or not, as well as shared or specialty specific surgical facilities was well defined. One hospital responded that their out-patient surgery was partially separated from in-patient surgery, and in the analyses this hospital has been classified as being organized without separate operating rooms for out-patient surgery.

Information on the number of surgeons in the different specialties and subspecialties at the different hospitals, were obtained from the national registry of the number of man-labour years in Norwegian hospitals ${ }^{[11]}$. This registry also specifies the number of consultants as well as interns and residents. The ratio of consultants to interns and residents were considered an indicator of the competence and qualifications of the surgical staff.

\subsection{Data analyses}

From the reported data operating room efficiency was calculated for total operating room efficiency, out-patient operating room efficiency and operating room efficiency during ordinary work hours.

In Norway, work contracts define doctors including surgeons and anesthesiologists as daytime workers, usually with an ordinary schedule from 7-8 am to 4-5 pm on weekdays, but with an obligation to participate in on-call systems to cover evenings, nights and weekends. Furthermore, according to the contracts, all medical activities after $5 \mathrm{pm}$ on weekdays can only include emergency procedures ${ }^{[12]}$. Because of this, it is considered that net effective operative hours for operating rooms in relation to elective surgery and daytime emergency cases is limited to seven hours ( $8 \mathrm{am}$ to $3 \mathrm{pm}$ ) on ordinary weekdays only. Taking also into consideration national and religious holidays as well as vacation time (five weeks for all and six weeks for employees older than 62 years), regular daytime work is limited to 230 effective workdays per year. Calculations of operating room efficiency were therefore related to these conditions when relevant.

\subsubsection{Productivity}

Productivity (operations per surgeon per year) was calculated by dividing total operation volume by the number of surgeons in each hospital. The ratios of surgeons to the number of operating rooms were also determined for each hospital.

\subsubsection{Surgeon competence}

Surgeon competence is an important factor in relation to both productivity and operating room efficiency. Consultants have more experience and knowledge than interns and residents. The per cent of consultants to total staff was therefore used to compare staff competence at the different hospitals.

\subsubsection{Total efficiency of operating rooms}

Total efficiency of operating rooms (operations per operating room per year) was calculated by dividing total operation volume by the number of operating rooms.

\subsubsection{Operating room efficiency for out-patient surgery}

Operating room efficiency for out-patient surgery was only calculated for hospitals with separate operating rooms for out-patient surgery and was based on 230 effective operative days per year as described above.

\subsubsection{Operating room efficiency for in-patient surgery during ordinary hours}

Calculations of operating room efficiency for in-patient surgery including emergency operations, was also based on a seven hour workday and 230 effective workdays per year. These calculations included all elective surgery as well as 
emergency operations during ordinary daytime. Based on reports from three of the hospitals in the study, emergency operations constituted $44 \%$ (range 36-50) of all operations not defined as out-patient surgery. Furthermore, a previous survey by one of the authors (DB) of the distribution of emergency operations at St. Olavs University Hospital and a study of emergency admissions to Akershus University Hospital ${ }^{[13]}$ showed that $48 \%$ of all emergency operations were performed during daytime and 52\% during evenings and nights. Provided that these daytime emergency operations are equally distributed throughout all seven weekdays, 5/7 (34\%) of all emergency operations are performed in daytime on Monday through Friday. On this background, 34\% of reported emergency operations were included in the daytime operation volume used to calculate operating room efficiency for ordinary hours and workdays for in-patient surgery.

\section{Statistical analysis}

Data were statistically analyzed with Student's test and Mann-Whitney U test (IBM SPSS version 20, Minitab version 16). Since no differences in statistical significance were found between these two tests, only results from Student's t-test are reported. Correlations were analyzed with Pearson's correlation coefficient using the same statistical software.

\section{Results}

Results are shown in Tables 1-6.

\subsection{Operating room efficiency in relation to surgical volume and number of operating rooms}

Since the study included hospital of significantly different size and surgical volume, operating room efficiency was analyzed in relation to operation volume and number of operating rooms. No correlation between operating room efficiency and operation volume or number of operating rooms could be found, with $\mathrm{R}=0,309, p=0,356$ and $\mathrm{R}=0.050$, $p=0,885$ respectively (data not shown).

Table 1. Organization of surgical services in Norwegian hospitals.

\begin{tabular}{|c|c|c|c|c|c|c|c|}
\hline $\begin{array}{l}\text { Hospital } \\
\text { ID }\end{array}$ & $\begin{array}{l}\text { Shared } \\
\text { use of } \\
\text { OR }\end{array}$ & $\begin{array}{l}\text { Separate OR for } \\
\text { out-patients } \\
\text { surgery }\end{array}$ & $\begin{array}{l}\text { Number of OR } \\
\text { for out-patient } \\
\text { surgery }\end{array}$ & $\begin{array}{l}\text { Out-patient } \\
\text { operations }\end{array}$ & $\begin{array}{l}\text { Total number of } \\
\text { OR in hospital }\end{array}$ & $\begin{array}{l}\text { Total number } \\
\text { of operations }{ }^{\dagger}\end{array}$ & $\begin{array}{l}\text { Total OR } \\
\text { efficiency }^{\dagger}\end{array}$ \\
\hline A & Yes & Yes & 10,2 & 10213 & 23.3 & 19059 & 818 \\
\hline B & Yes & Yes & 8 & 6918 & 22 & 14932 & 678 \\
\hline $\mathrm{C}$ & No & Yes & 13 & 9615 & 38 & 29401 & 774 \\
\hline D & No & No & & 8139 & 19 & 15629 & 823 \\
\hline $\mathrm{E}$ & No & No & & 2894 & 14 & 10536 & 753 \\
\hline $\mathrm{F}$ & Yes & No & & 2668 & 12 & 8769 & 681 \\
\hline G & No & Yes & 14 & 12878 & 35 & 23500 & 671 \\
\hline $\mathrm{H}$ & No & Yes & 12 & 10221 & 35 & 26895 & 768 \\
\hline I & Yes & Yes & 2,5 & 1882 & 13 & 6821 & 525 \\
\hline $\mathrm{K}$ & No & Yes & 20 & 13294 & 48 & 28507 & 594 \\
\hline $\mathrm{L}$ & No & Yes & 3 & 2283 & 15 & 9445 & 623 \\
\hline
\end{tabular}

tincludes out-patient, in-patient and emergency operations.

Characteristics of organization of surgical facilities and services (shared use of operating rooms (OR) by different subspecialties or subspecialty specific OR; separate or shared OR for outpatient surgery), number of operating rooms (OR), surgical volume (total operations and out-patient operations), and total OR efficiency (operations per OR per year, mean \pm SD) in 2009 in eleven Norwegian hospital with a similar mix of surgical subspecialties. 


\subsection{Organization of surgical services in Norwegian hospitals}

As shown in Table 1, the study included hospitals with a large variation in patient volume, number of operating rooms and total operating room efficiency. For some hospitals the number of operating rooms is given with a decimal due to information on partial use of some rooms through the weekdays.

Table 2. Surgical staff, competence and productivity in eleven large Norwegian county and university hospitals

\begin{tabular}{|c|c|c|c|c|c|c|c|c|c|}
\hline \multirow{3}{*}{$\begin{array}{l}\text { Hospital } \\
\text { ID }\end{array}$} & \multirow{3}{*}{$\begin{array}{l}\text { Total } \\
\text { operations }\end{array}$} & \multirow{3}{*}{$\begin{array}{l}\text { Total } \\
\text { number of } \\
\text { surgeons }\end{array}$} & \multirow{3}{*}{$\begin{array}{l}\text { Consultants as } \\
\text { percentage of } \\
\text { total staff }\end{array}$} & \multirow{3}{*}{$\begin{array}{l}\text { Total } \\
\text { operating } \\
\text { rooms }\end{array}$} & \multirow{3}{*}{$\begin{array}{l}\text { Surgeons } \\
\text { per } \\
\text { operating } \\
\text { room }\end{array}$} & \multicolumn{4}{|c|}{ Productivity } \\
\hline & & & & & & \multicolumn{2}{|c|}{ Shared use of OR } & \multicolumn{2}{|c|}{$\begin{array}{l}\text { Out-patient in } \\
\text { separate OR }\end{array}$} \\
\hline & & & & & & Yes & No & Yes & No \\
\hline A & 19059 & 105 & 61,4 & 23.3 & 4,5 & 182 & & 182 & \\
\hline B & 14932 & 107 & 62,6 & 22 & 4,9 & 140 & & 140 & \\
\hline $\mathrm{C}$ & 29401 & 204,5 & 62,3 & 38 & 5,4 & & 144 & 144 & \\
\hline $\mathrm{D}$ & 15629 & 78,4 & 59,2 & 19 & 4,1 & & 199 & & 199 \\
\hline E & 10536 & 62 & 58,0 & 14 & 4,4 & & 170 & & 170 \\
\hline $\mathrm{F}$ & 8769 & 55 & 60,9 & 12 & 4,6 & 159 & & & 159 \\
\hline G & 23500 & 148 & 61,1 & 35 & 4,3 & & 121 & 121 & \\
\hline $\mathrm{H}$ & 26895 & 221,9 & 60,1 & 35 & 6,3 & & 142 & 142 & \\
\hline I & 6821 & 57 & 54,4 & 13 & 4,4 & 120 & & 120 & \\
\hline K & 28507 & 200,15 & 65,3 & 48 & 4,2 & & 142 & 142 & \\
\hline \multirow[t]{2}{*}{$\mathrm{L}$} & 9445 & 66 & 61,4 & 15 & 4,4 & & 143 & 143 & \\
\hline & & & $60,6 \pm 2,8$ & & $4,7 \pm 0,6$ & $150 \pm 26 \#$ & $150 \pm 24 \#$ & $144 \pm 19$ & $176 \pm 21^{*}$ \\
\hline
\end{tabular}

* $P=0.107$ versus separate out-patient $\mathrm{OR}, \# \mathrm{p}=0,161$ versus out-patient $\mathrm{OR}$ not separated

Data is given for total operations, total staff, and staff competence (consultants as percentage of total staff). Productivity (operations per surgeon per year) is given separately for hospitals with or without shared use of operating rooms (OR) and separate or not separate out-patient OR.

Table 3. Operating room efficiency in hospitals organized with separate or shared operating rooms for out-patient services

\begin{tabular}{|c|c|c|c|c|c|c|c|}
\hline \multicolumn{3}{|c|}{ All hospitals } & \multicolumn{3}{|c|}{ Separate OR for out-patient surgery } & \multicolumn{2}{|c|}{ Out-patient OR not separated } \\
\hline $\begin{array}{l}\text { Hospital } \\
\text { ID }\end{array}$ & $\begin{array}{l}\text { Separate OR for } \\
\text { out-patient } \\
\text { surgery }\end{array}$ & $\begin{array}{l}\text { Out-patient } \\
\text { operations }\end{array}$ & $\begin{array}{l}\text { OR efficiency for } \\
\text { out-patient surgery }\end{array}$ & $\begin{array}{l}\text { Total } \\
\text { operations }^{\dagger}\end{array}$ & $\begin{array}{l}\text { Total OR } \\
\text { efficiency }^{\dagger}\end{array}$ & $\begin{array}{l}\text { Total } \\
\text { operations }^{\dagger}\end{array}$ & $\begin{array}{l}\text { Total OR } \\
\text { efficiency }^{\dagger}\end{array}$ \\
\hline A & Yes & 10213 & 1001 & 19059 & 818 & & \\
\hline G & Yes & 12878 & 920 & 23500 & 671 & & \\
\hline B & Yes & 6918 & 865 & 14932 & 678 & & \\
\hline $\mathrm{H}$ & Yes & 10221 & 851 & 26895 & 768 & & \\
\hline $\mathrm{L}$ & Yes & 2283 & 761 & 9445 & 623 & & \\
\hline I & Yes & 1882 & 753 & 6821 & 525 & & \\
\hline $\mathrm{C}$ & Yes & 9615 & 740 & 29401 & 774 & & \\
\hline $\mathrm{K}$ & Yes & 13294 & 665 & 28507 & 594 & & \\
\hline $\mathrm{D}$ & No & 8139 & & & & 15629 & 823 \\
\hline $\mathrm{E}$ & No & 2894 & & & & 10536 & 753 \\
\hline $\mathrm{F}$ & No & 2668 & & & & 8769 & 681 \\
\hline \multicolumn{3}{|c|}{ Mean \pm SD } & $820 \pm 110^{\#}$ & & $681 \pm 100^{*}$ & & $752 \pm 71$ \\
\hline
\end{tabular}

†includes out-patient, in-patient as well as emergency operations; * $p=0.247$ compared to hospitals without separate OR for out-patient surgery; \# $\#=0.020$ compared to total OR efficiency Data show total operation volume, out-patient operation volume and total operating room (OR) efficiency (operations/OR/year) in eight hospitals with separate OR for out-patient surgery and three hospitals without separate OR for out-patient surgery. For hospital with separate OR for out-patient surgery, OR efficiency is also given for out-patient surgery.

Table 1 also shows that most hospitals (8/11) had organized out-patient surgery with operating rooms separated from in-patient surgical services. Most hospitals (7/11) also had specific operating rooms for different subspecialties. There was no fixed association between these two strategies for organization within the different hospitals. Furthermore, the 
organization of surgical services in relation to these two strategies did not seem to have any effect on operating room efficiency. These issues are further analyzed in Tables 3, 4 and 5.

Table 4. Operating room efficiency in hospitals organized with shared or subspecialty specific operating rooms

\begin{tabular}{|c|c|c|c|c|c|}
\hline \multicolumn{2}{|l|}{ All hospitals } & \multicolumn{2}{|c|}{ Shared use of OR between subspecialties } & \multicolumn{2}{|c|}{ Subspecialty specific OR } \\
\hline Hospital ID & Shared use of OR & Total operations $^{\dagger}$ & Total OR efficiency $^{\dagger}$ & Total operations $^{\dagger}$ & Total OR efficiency $^{\dagger}$ \\
\hline A & Yes & 19059 & 818 & & \\
\hline B & Yes & 14932 & 678 & & \\
\hline I & Yes & 6821 & 525 & & \\
\hline $\mathrm{F}$ & Yes & 8769 & 681 & & \\
\hline $\mathrm{C}$ & No & & & 29401 & 774 \\
\hline $\mathrm{H}$ & No & & & 26895 & 768 \\
\hline $\mathrm{L}$ & No & & & 9445 & 623 \\
\hline G & No & & & 23500 & 671 \\
\hline K & No & & & 28507 & 594 \\
\hline $\mathrm{D}$ & No & & & 15629 & 823 \\
\hline $\mathrm{E}$ & No & & & 10536 & 753 \\
\hline Mean \pm SD & & & $629 \pm 105^{*}$ & & $715 \pm 86$ \\
\hline
\end{tabular}

†includes out-patient, in-patient as well as emergency operations

* $p=0.222$ versus subspecialty specific OR

Data show total operation volume, and operating room (OR) efficiency (operations/OR/year) in four hospitals with shared use of OR between subspecialties and seven hospitals organized with subspecialty specific OR.

\subsection{Competence and productivity of surgical staff}

Table 2 gives an overview of competence of surgical staff and productivity in relation to operation volume in included hospitals. As shown in the table, the percent of consultants to total surgical staff were similar between hospitals. Productivity (operations per surgeon per year) was also quite similar and was not related to the different strategies for organization of surgical services. Furthermore, the ratios of surgeons to operating rooms were also similar between hospitals.

\subsection{Operating room efficiency in hospitals with separate operating rooms for out-patient surgery}

Table 3 shows operating room efficiency in hospitals organized with separate operating rooms for out-patient surgery compared to hospitals without such organization. Total operating room efficiency was not significantly different between these two groups of hospitals. In hospitals with separate operating rooms for out-patient surgery, out-patient operating room efficiency was higher than total operating room efficiency.

\subsection{Operating room efficiency in hospitals organized with subspecialty specific operating rooms}

Table 4 shows operating room efficiency in hospitals with shared use of operating rooms between different subspecialties compared to hospitals with subspecialty specific operating rooms. No significant differences in operating room efficiency could be found between these two different strategies for organizing the surgical facilities.

The results in Tables 3 and 4 are further analyzed in Table 5, where different combinations of organizational strategies are analyzed. Five hospitals had separate out-patient and subspecialty specific operating rooms (A); three hospitals had separate out-patient facilities but shared operating rooms between different subspecialties (B); two hospitals did not separate out-patient surgery from in-patient surgery and also shared operating rooms between different subspecialties (C); while only one hospital was organized with without separate out-patient facilities but had subspecialty specific operating 
rooms (D). As can be seen from the table, no significant differences in operating room efficiency could be found between these different strategies. Productivity was also similar (data not shown).

Table 5. Operating room efficiency according to strategies for organization of in-patient and out-patient services

\begin{tabular}{|c|c|c|c|c|c|c|c|c|}
\hline \multirow[b]{3}{*}{ Hospital ID } & \multicolumn{2}{|l|}{ A } & \multicolumn{2}{|l|}{ B } & \multicolumn{2}{|l|}{ C } & \multicolumn{2}{|l|}{ D } \\
\hline & \multicolumn{2}{|c|}{$\begin{array}{l}\text { Separate out-patient } \mathrm{OR} \text {, } \\
\text { subspecialty specific OR }\end{array}$} & \multicolumn{2}{|c|}{$\begin{array}{l}\text { Separate out-patient OR, } \\
\text { shared OR between } \\
\text { subspecialties }\end{array}$} & \multicolumn{2}{|c|}{$\begin{array}{l}\text { Out-patient OR not } \\
\text { separated, shared OR } \\
\text { between subspecialties }\end{array}$} & \multicolumn{2}{|c|}{$\begin{array}{l}\text { Out-patient OR not } \\
\text { separated, subspecialtiy } \\
\text { specific OR }\end{array}$} \\
\hline & Operations $^{\dagger}$ & $\begin{array}{l}\text { OR } \\
\text { efficiency }^{\dagger}\end{array}$ & Operations $^{\dagger}$ & $\begin{array}{l}\text { OR } \\
\text { efficiency }^{\dagger}\end{array}$ & Operations $^{\dagger}$ & $\begin{array}{l}\text { OR } \\
\text { efficiency }^{\dagger}\end{array}$ & Operations $^{\dagger}$ & $\begin{array}{l}\text { OR } \\
\text { efficiency }^{\dagger}\end{array}$ \\
\hline A & & & 19059 & 818 & & & & \\
\hline B & & & 14932 & 678 & & & & \\
\hline C & 29401 & 774 & & & & & & \\
\hline D & & & & & 15629 & 823 & & \\
\hline E & & & & & 10536 & 753 & & \\
\hline F & & & & & & & 8769 & 681 \\
\hline G & 23500 & 671 & & & & & & \\
\hline $\mathrm{H}$ & 26895 & 768 & & & & & & \\
\hline I & & & 6821 & 525 & & & & \\
\hline K & 28507 & 594 & & & & & & \\
\hline $\mathrm{L}$ & 9345 & 623 & & & & & & \\
\hline Mean \pm SD & $23530 \pm 8243$ & $686 \pm 82$ & $13604 \pm 6226$ & $674 \pm 147$ & $\begin{array}{l}13083 \pm 3 \\
601\end{array}$ & $788 \pm 49$ & 8769 & 681 \\
\hline
\end{tabular}

tincludes out-patient, in-patient as well as emergency operations

OR efficiency: A versus B: $p=0.909$; $\mathrm{A}$ versus $\mathrm{C}: p=0.136$; $\mathrm{B}$ versus $\mathrm{C}: 0.410$, A versus $(\mathrm{B}+\mathrm{C}+\mathrm{D}): p=0.657$

Total operations and operating room (OR) efficiency in relation to four different combinations of strategies for organizing surgical services in eleven Norwegian hospitals; with or without separate OR for out-patient surgery and shared or

subspecialty specific $\mathrm{OR}$.

\subsection{Operating room efficiency on ordinary hours and workdays}

Table 6 shows operating room efficiency during ordinary hours (8 am - 3 pm) and 230 effective workdays per year as described earlier. Data is given for out-patient surgery (only for hospitals with separate out-patient operating rooms) and for in-patient surgery (including emergency operations) as well as for total operations (out-patient surgery and in-patient surgery combined) for all hospitals. As shown, operating room efficiency varies considerably between hospitals, but is generally much higher for out-patient surgery than for in-patient surgery. Including emergency operations, the total operating room efficiency for in-hospital surgery during ordinary hours and workdays in Norwegian hospitals is between 2 -3 operations per operating room per day.

Table 6. Operating room efficiency during ordinary work hours and weekdays

\begin{tabular}{|c|c|c|c|}
\hline Hospital ID & $\begin{array}{l}\text { OR efficiency for } \\
\text { out-patient surgery }\end{array}$ & $\begin{array}{l}\text { OR daytime efficiency for } \\
\text { in-hospital surgery }^{\dagger}\end{array}$ & $\begin{array}{l}\text { Total daytime OR efficiency in } \\
\text { hospital }^{++}\end{array}$ \\
\hline A & 4,4 & 2,0 & 3,0 \\
\hline B & 3,8 & 1,8 & 2,5 \\
\hline $\mathrm{C}$ & 3,2 & 2,4 & 2,7 \\
\hline D & - & & 3,0 \\
\hline E & - & & 2,0 \\
\hline $\mathrm{F}$ & - & & 2,5 \\
\hline G & 4,0 & 1,6 & 2,5 \\
\hline $\mathrm{H}$ & 3,7 & 2,2 & 2,7 \\
\hline I & 3,3 & 1,3 & 1,7 \\
\hline K & 2,9 & 1,2 & 2,2 \\
\hline $\mathrm{L}$ & 3,2 & 1,8 & 2,1 \\
\hline Mean \pm SD & $3,6 \pm 0,5^{*}$ & $1,8 \pm 0,4$ & $2,4 \pm 0,4^{\#}$ \\
\hline
\end{tabular}

${ }^{*} p<0.001$ versus in-hospital surgery; $\# p=0.002$ versus outpatient surgery; †includes in-patient surgery and emergency operations during regular daytime; $\dagger+$ includes out-patient surgery, in-patient surgery and emergency operations during regular daytime 


\section{Discussion}

This study includes large and medium sized Norwegian hospitals spread around the country, from east to west and north to south and with a similar mix of different surgical subspecialties. On the other hand, the hospitals in the study showed a large variation in surgical volume and number of operating rooms, which could influence upon the results. Furthermore, the small and unbalanced number of hospitals in the different groups could also influence the results of the statistical comparisons. However, no difference in productivity could be found between the hospitals and competence measured as the percentage of consultants to total surgical staff was also similar. The study data should therefore be representative for surgical services in Norwegian hospitals. Also, since no correlation between operating room efficiency and number of operating rooms or surgical volume was found, such differences have probably only minor effects on the results. Furthermore, by comparing operating room efficiency between the five hospitals with separate out-patient facilities and subspecialty specific operating rooms with the remaining six hospitals with other combinations of strategies as shown in Table 5 (group A versus groups B, C and D combined), no difference in total operating room efficiency or productivity could be found.

A major finding in the study is the significant variation in operating room efficiency between Norwegian hospitals. This has previously been shown in a study of 12 county and local hospitals in relation to the problem of cancellations ${ }^{[14]}$. In that study the number of operations per operating room per year varied from 614 to 1,307 operations with a mean of 754 operations. In the present study the variation was from 525 to 823 operations, with an average of 701 operations per operating room per year. The somewhat lower volume in the present study can be explained by the inclusion in this study of university hospitals and larger county hospitals with probably a higher number of complicated operations needing longer time in the operating room.

\subsection{Does organization on the macro level influence operating room efficiency?}

Based on the present results it does not seem that the organization of surgical services on the macro level (separate or not separate operating rooms for out-patient surgery, shared or specialty specific operating rooms) has any impact on operating room efficiency. All hospitals in the study with separate facilities for out-patient surgery had, however, higher operating room efficiency for out-patient surgery than for in-patient surgery (Table 5). This finding can probably be explained by the fact that out-patient operations are usually simpler and the patients healthier than in in-patient surgery and has no relation the organization of the services. On the other hand, although not statistically significant, both productivity (Table 2) and total operating room efficiency (Table 3) tended to be higher in hospitals where out-patient surgery was not organized with separate operating rooms ( $p=0.107$ versus separate out-patient OR for both comparisons). This might indicate that an organization with separate operating rooms for out-patient surgery may results in reduced flexibility in the use of the total facilities. This should be further studied in a larger number of comparable hospitals.

The present study did not include any analysis of possible differences between hospitals related to organization on the micro level such as cancellations, turnover time, time needed per operation, non-operative time, tardiness, and factors related to team members cooperation, motivation and discipline, which have been shown to be of significant importance for operating room efficiency (1-9). The relatively large differences in operating room efficiency also between hospitals of similar size, implies that operating room efficiency is more related to differences on the micro level. This is also supported by the finding that operating room efficiency was not increased in hospitals with increased number of surgeons per operating room ( $\mathrm{R}=0.300, p=0.371)$. It was thus recently reported from a small Norwegian hospital (not included in this study) that through a combination of a reduction in cancellations from 10.2 to $6.9 \%$ and a reduction in case duration of approximately one hour, operating room efficiency significantly improved, and $40 \%$ more patients were operated without any increase in staff or other resources ${ }^{[15]}$. The large variation in operating room efficiency between hospitals found in the present study therefore indicates that many hospitals have a potential for improvement of operating room efficiency by similar initiatives. 


\subsection{Actual operating room efficiency versus planning standards}

Plans for new hospitals are based on a number of conditions in relation to anticipated patient volume as well as standards for space usage and occupation rates. When planning facilities for surgical services it has in Norway been common to plan for a 7 hour daily activity during 230 effective workdays per year ${ }^{[16-20]}$. Average case duration plus turnover time has been set at a standard of 120 (100-150) minutes for in-hospital elective patients and 80 (70-90) minutes for out-patient surgery, with some variation between different recently planned hospitals ${ }^{[15-19]}$. According to these standards, operating room efficiency during ordinary work hours should be between 5-7 out-patient and 3-5 in-patient operations per operating room per day. The results of the present study show, however, that the actual operating room efficiency in Norwegian hospitals is less than half of these standards (Table 5). This finding can be considered in two ways; either is the operating room efficiency found in the present study much too low, or, present standards for operating room efficiency are too optimistic or unrealistic. In our view, the large variation shown in operating room efficiency in the present study favors the conclusion that many hospitals have a potential for significantly improving operating room efficiency, as recently demonstrated ${ }^{[14]}$. If so, it can also be concluded that many hospitals have overinvested in operating rooms. If, on the other hand, the conclusion is that standard hospital plans have a too optimistic view on operating room efficiency, there is a possibility that hospitals now being planned will be built with too few operating rooms. This could result in significant problems for the surgical services. From this point of view it is important that the surgical facilities are planned and built with a large degree of flexibility so they can easily be rebuilt or expanded compared to original plans.

With a gross average area of 200-250 square meter per operating room at an investment cost between 10 000-15 000 € per square meter medical equipment included, the cost of an operating room in Norway totals between 2-3.3 million $€$. To give the hospital a return value for such an investment, these facilities need to be efficiently operated. Operating room efficiency is a critical factor in all hospitals, and has direct impact on patient survival rate and health. Underinvestment in this sector will therefore also be critical for both the hospital as well as its patients.

\section{Competing interests}

None of the authors have received reimbursements, fees or salary from any organization or hold shares in any company which may gain or lose financially from the publication of this manuscript.

\section{Authors' contribution}

Both authors DB and SPR planned the study and developed the questionnaire. DB distributed the questionnaire to the hospital contacts and was responsible for most of the follow-up and data accretion. Both authors were equally responsible for data analysis and writing of the manuscript.

\section{References}

[1] Mathias JM Benchmarking OR turnover times. OR Manager. 2000; 16: 18-20.

[2] Aaserud M, Trommald M, Boynton J. Elektiv kirurgi - strykninger, skjerming og effektivitet. Tidsskr Nor Lægeforen. 2001; 121: 2516-9. PMid:11875930

[3] Dexter F, Marcario A. When to release allocated operating room time to increase operating room efficiency. Anesth Analg. 2004; 98: 758-62. PMid:14980933 http://dx.doi.org/10.1213/01.ANE.0000100739.03919.26

[4] Sandberg WS, Daily B, Egan M et al. Deliberate perioperative systems design to improve operating room throughput. Anesthesiology. 2005; 103: 405-18. http://dx.doi.org/10.1097/00000542-200508000-00025

[5] Harders M, Malangoni MA, Weight S et al. Improving operating room efficiency through process redesign. Surgery. 2006; 140: 509-16. PMid:17011897 http://dx.doi.org/10.1016/j.surg.2006.06.018

[6] Marjamaa R, Vakkuri A, Kirvela O. Operating room management: why, how and by whom? Acta Anaesthesiol Scand. 2008; 52: 596-600. PMid:18419711 http://dx.doi.org/10.1111/j.1399-6576.2008.01618.x

[7] Arakelian E, Gunningberg L, Larsson J. How operating room efficiency is understood in a surgical team: a qualitative study. Int J Qual Health Care. 2011; 23: 100-106. PMid:21098628 http://dx.doi.org/10.1093/intqhc/mzq063 
[8] Cima RR, Brown MJ, Hebl JR et al. Use of lean and six sigma methodology to improve operating room efficiency in a high-volume tertiary-care academic medical center. J Am Coll Surg. 2011; 213: 83-92. PMid:21420879 http://dx.doi.org/10.1016/j.jamcollsurg.2011.02.009

[9] Peters JA, Dean HM. Enhancing OR capacity and utilization. Healthc Financ Manage. 2011; 65: 66-71. PMid:21351711

[10] Rasmussen K, Bratlid D. Quality or equality? The Norwegian experience with medical monopolies. BMC Health Services Research. 2007 Feb 15; 7: 20. PMid:17302967 http://dx.doi.org/10.1186/1472-6963-7-20

[11] www.nrbasen.helsedirektoratet.no (Norwegian Health Directory Database).

[12] Bratlid D. Are doctor's work schedules appropriate? Tidsskr Nor Legeforen. 2012; 132: 1590-1. PMid:22875119 http://dx.doi.org/10.4045/tidsskr.12.0522

[13] Schioldborg S. Minicase AHUS - prosessforbedring ved akuttmottaksenheten. Oslo: Deloitte, 2007.

[14] Hauge HN. Strøket av programmet. Master Thesis. Center for Health Administration, Faculty of Medicine, University of Oslo, 1998.

[15] Nilsen L. Omorganiserte - og opererte 40 prosent flere pasienter. Dagens medisin. 2011 October 13; 11: 4-5.

[16] Helsebygg Midt-Norge. 2003. Main Functional Programme, St.Olavs University Hospital, phase 2.

[17] New Akershus University Hospital. 2003. Main Functional Programme.

[18] New Østfold county hospital. 2008. Main Functional Programme.

[19] Helse Stavanger HF. 2010. Masterplan Stavanger University Hospital.

[20] Oslo University Hospital. 2011. Masterplan. 